Est Ag 55 (2020) 5-29

\title{
La caracterización de Judas Iscariote en el evangelio de Juan
}

\author{
José Manuel Hernández CARraCedo
}

RESUMEN: El evangelio de Juan realiza una relectura original de Judas Iscariote. En este trabajo se compara la caracterización joánica del hombre "que entregó" a Jesús con la de los Sinópticos. De esta forma, podemos descubrir y estudiar la especificidad de la puesta en escena de Judas en el cuarto evangelio. La originalidad del relato joánico radica tanto en la forma de presentar a Judas (enunciación) como en los rasgos teológicos que lo definen. Por último, se presentará la hipótesis de que el "Judas del cuarto evangelio" refleja a grupos judeocristianos distintos de los grupos joánicos o escindidos de ellos.

Palabras Clave: Evangelio de Juan, Comunidades Joánicas, Notas del narrador, Judas Iscariote, Judeocristianismo.

ABSTRACT: The Gospel of John realizes an original rereading of Judas Iscariot. This work compares the Johannine characterization of the man "who gave" Jesus to that of the Synoptics. In this way, we can discover and study the specificity of the staging of Judas in the fourth gospel. The originality of the Johannine story lies both in the way of presenting Judas (enunciation) and in the theological features that define it. Finally, we will present the hypothesis that the "Judas of the fourth gospel" reflects Judeo-Christian groups other than the Johannine groups or split from them.

Keywords: Gospel of John, Johannine Communities, Notes from the Narrator, Judas Iscariot, Judeo-Christianity. 


\section{INTRODUCCIÓN}

Judas es mencionado 22 veces en los evangelios: tres en Marcos, cinco en Mateo, seis en Lucas y ocho en Juan. El número progresivo de comparecencias revela un creciente interés por este personaje en la tradición evangélica ${ }^{1}$.

Pese a ello, su figura histórica sigue siendo un misterio. Solo poseemos dos datos fiables: formaba parte de los Doce y entregó a su Maestro a las autoridades judías ${ }^{2}$. Ni tan siquiera el significado de su sobrenombre, Iscariote, está próximo a aclararse. Que Jesús hubiese elegido discípulo a aquel que a la postre le entregó tuvo que crear preguntas y tensiones en el seno de las comunidades cristianas ${ }^{3}$.

El "Judas del evangelio" refleja, sin duda, menos las motivaciones del Judas histórico que la de los evangelistas. Cada evangelio relee el personaje mostrando un perfil de sus preocupaciones cristológicas o eclesiológicas $^{4}$. En este trabajo se estudia la interpretación que realiza el cuarto evangelio de Judas. Una relectura profunda, pues en el relato aparecen diseminados todos los motivos presentes en los evangelios sinópticos y, sobre todo, todas las apariciones de Judas se encuentran en las notas del narrador o en escenas que son comentadas por él.

\section{JUdAS EN Los Evangelios Sinópticos}

\section{Judas en el evangelio de Marcos}

En este evangelio aparece la información básica del papel de Judas en la muerte de Jesús. Es él el que toma la iniciativa de entregarlo a las autoridades judías, que le ofrecen dinero por ese servicio (Mc 14,10-11).

${ }^{1}$ Di BIANCO, Nicola - GRIMALdi, Emma, "Giuda Iscariota tra memorie neotestamentarie e interpretazioni letterarie" en Asprenas 65 (2018) 313-336.

${ }^{2}$ MeIER, John P., Un judío marginal. Nueva visión del Jesús Histórico. Compañeros y competidores, III, Verbo Divino, Estella 2003, 225.

${ }^{3}$ Dunn, James, Jesús recordado. El cristianismo en sus comienzos, Verbo Divino, Estella 2009,868 .

${ }^{4}$ Descreaux, Jacques, "Approche narrative du personnage de Judas en Marc, Mathieu et Luc-Actes" en Theophilon XIX-1 (2014) 39-57. 
Jesús afirma que va a ser entregado por uno de los Doce (Mc 14,18-21) lo que supondrá el cumplimiento de la misteriosa voluntad divina $(\mathrm{Mc} 9,31)^{5}$.

Hay que destacar que la expresión "uno de los Doce" aparece en la voz de Jesús, no del narrador. Y que no se desvela la identidad del traidor a los personajes en ningún momento de la narración hasta la escena del prendimiento ${ }^{6}$.

\section{Judas en el evangelio de Mateo}

A los datos de Marcos, Mateo añade la cuantía del dinero que Judas recibe de las autoridades (Mt 26,14-16). Jesús sí que identifica al traidor (Mt 26,25). En la escena del prendimiento aparece una expresión en boca de Jesús que es interpretada como un encargo o una orden (Mt 26,50). Mateo presenta el arrepentimiento y el trágico final de Judas (Mt 27,3-5) que son comentados ampliamente por el narrador y relacionados con la Escritura (Mt 27,8-10).

La novedad es que Judas pide dinero a cambio de entregar a Jesús, por lo que la avaricia aparece como motivación de su traición. Por otro lado, Jesús no solo conoce que va a ser entregado, sino que también sabe quién lo hará.

\section{Judas en el evangelio de Lucas}

A lo largo de su relato Lucas muestra la influencia de las fuerzas sobrenaturales sobre los personajes. No es extraño que su primera información sobre Judas sea la influencia de Satanás (Lc 22,3). De esta forma, se justifica su acercamiento a las autoridades judías para entregar a Jesús (Lc 22,4-6). Este conoce que va a ser entregado, pero no identifica al traidor, algo que se puede entender dada la tendencia de Lucas de disimular los defectos de los Doce. En la escena del prendimiento Jesús descifra el beso de Judas como el signo de la traición (Lc 22,47-48). Lucas no menciona el destino de Judas en el evangelio, sino en el libro de los Hechos de los

\footnotetext{
${ }^{5}$ Gathercole, Simon, The Gospel of Judas Rewriting Early Christianity, Oxford University Press, Oxford 2007.

${ }^{6}$ Los lectores de los sinópticos conocen al traidor desde su aparición de la lista de los apóstoles Mc 3,13-19; Mt 10,1-4; Lc 6,12-16.
} 
Apóstoles (Hch 1,15-20), y aunque presenta diferencias con Mateo hay motivos que se repiten: la compra de un campo, el papel de la Escritura.

La especificidad de Lucas es la introducción de Satanás en el proceso de entrega.

\section{Conclusión}

Los relatos de los evangelios sinópticos son unánimes en sus afirmaciones de que Judas Iscariote es el discípulo que entregó a Jesús. Con el paso del tiempo, la caracterización de Judas se va enfatizando: a las primeras afirmaciones de Marcos, Mateo añade el motivo de la avaricia y el destino fatal del apóstol, y Lucas añade el elemento sobrenatural de satanás. Desde una misteriosa motivación humana se llega a una causa sobrenatural con la que Judas colabora libremente.

\section{Judas En El Evangelio de Juan}

El cuarto evangelio continúa con la enfatización en la caracterización de Judas. El indicio más firme para llegar a esta conclusión es el modo en el que Juan presenta a Judas. Siempre aparece dentro de notas del narrador o en versículos que son comentados a continuación? Las notas son una información adicional del narrador, que al interrumpir la secuencia narrativa queda focalizada ${ }^{8}$.

\section{La presentación narrativa de Judas en el evangelio de Juan}

Las apariciones iniciales de Judas en el relato son Jn 6,64 y Jn 6,71. Ambas notas del narrador. En la primera, Jesús es consciente de que va a ser entregado. En la segunda se identifica al traidor como Judas, Hijo de Simón Iscariote y uno de los Doce.

${ }^{7}$ Thatcher, Tom, "Jesus, Judas and Peter: Character by Contrast in the Fourth Gospel" en Biblioteca Sacra 153 (1996) 435-448, 436.

${ }^{8}$ HernÁndez, José Manuel, “La caracterización de Jesús en las notas del narrador y su papel en el relato del cuarto evangelio" en Estudio Agustiniano 55 (2017) 173-205, 186. 
Vuelve a comparecer en el episodio de la Unción de Jesús en Betania (Jn 12,1-8). En 12,4 Judas critica el gesto de María hacia Jesús. A renglón seguido, el narrador anota que a Judas no le importaban los pobres, sino que era un ladrón que robaba el dinero de la bolsa común, que él llevaba.

En el capítulo 13 su presencia se acentúa. En 13,2 el narrador anuncia que el diablo ha puesto en Judas el propósito de entregar a Jesús. En 13,11 comentando las palabras de Jesús a Pedro, identifica a Judas como aquel que no está limpio. Más adelante, Jesús alude al traidor mediante una cita de la Escritura y a continuación anuncia que va a ser entregado por uno con los que comparte su mesa (Jn13,18). En el instante que Jesús entrega el pan a Judas y lo come, el narrador informa al lector, que el diablo entró en el discípulo, convirtiéndose en un endemoniado. En ese momento, Jesús se dirige a él con una expresión ambigua (Jn 13,27). Finaliza la escena con una nueva nota, Jn 13,29, en la que se aclara que los discípulos no llegaron a identificar al traidor, sino que entendieron la expresión de Jesús como un mandato de dar limosna a los pobres o realizar alguna compra. El episodio termina con la salida de Judas de la casa y una nueva nota del narrador: "Era de noche" (Jn 13,30).

Jn 17,12 parece aludir a Judas. Jesús declara que uno de sus discípulos se ha perdido. Esta afirmación se explicita en la escena del prendimiento. El narrador informa que Judas conocía también el lugar (Jn 18,2) y al salir Jesús al encuentro del grupo que le viene a apresar les ordena que dejen libre a los discípulos, algo que como señala el narrador en una nueva nota $($ Jn 18,9) trae consigo el cumplimiento de una palabra de Jesús, que el lector descubre en Jn 17,12. Así pues, el único discípulo que no puede ser liberado es Judas.

La última referencia a Judas aparece en el epílogo del evangelio. En Jn 21,20 el discípulo amado es caracterizado como aquel que preguntó a Jesús por la identidad del traidor y por lo tanto el único que llegó a conocerla.

Se puede descubrir una cierta línea narrativa en estas notas. Las dos primeras presentan al personaje asociado a los que no creen en la palabra de Jesús, especialmente a las del significado del pan de vida y es identificado con un diablo (Jn 6,64.71). De esta manera puede ser presentado en la cena como alguien que "no está limpio" y se puede entender su difícil relación con el pan y su posesión satánica. Al permanecer en el grupo de 
los Doce y no abandonar a Jesús, el lector capta que es un mentiroso e hipócrita, lo cual se hace evidente en la escena de la unción en Betania donde se añade el motivo del robo de la bolsa común. Es su papel de tesorero el que permite la salida de Judas a perpetrar la traición, sin que los discípulos sospechen su objetivo. La revelación de la identidad del traidor al discípulo amado hace posible que en el capítulo 21 este personaje sea caracterizado como el poseedor único de esa información.

\section{Semejanzas y diferencias entre el Evangelio de Juan y los Sinópticos}

a) Comparación entre la tradición sinóptica y el evangelio joánico

Se puede afirmar que todo el material sinóptico referido a Judas aparece en el relato joánico, pero situado narrativamente de forma diversa ${ }^{9}$.

Judas es presentado como el que entregó a Jesús y como miembro de los Doce. La novedad joánica es que el sobrenombre, Iscariote, procede del padre, Simón Iscariote, que en los sinópticos no se menciona.

Aparece el motivo del dinero, pero no como recompensa de su traición por parte de las autoridades judías, sino producto del robo del dinero del grupo.

Jesús conoce desde el principio que va a ser entregado. Solo en $\mathrm{Mt}$ Jesús identifica ante los apóstoles al traidor mientras que Mc y Lc no aclaran si Jesús conocía al traidor. En cambio, en Jn, salvo el discípulo amado, no llegan a conocer su identidad antes del prendimiento.

Lucas y Juan coinciden en el papel del demonio en la entrega de Jesús.

${ }^{9}$ Algunos de estos datos también aparecen en el Evangelio de Judas. Judas es presentado con la misma fórmula de identificación; Jesús conoce y anuncia (u ordena) a Judas su entrega, aparecen las autoridades judías que le dan dinero. Otro dato adicional es que en el evangelio apócrifo aparece una dura tensión con los Doce y con las prácticas rituales como la Eucaristía (BERMEJo, Fernando, El evangelio de Judas. Texto bilingüe y comentario, Sígueme, Salamanca 2012). 
La posible instrucción a Judas que aparece en el evangelio de Mateo en la escena del prendimiento se anticipa en la cena joánica y provoca su salida de la casa.

El destino trágico de Judas no es narrado, pero puede aparecer implícito en las palabras de Jesús en la oración sacerdotal (Jn 17,12).

\section{b) Novedades en el evangelio de Juan}

Algunas de las novedades del relato joánico ya han sido presentadas. Ahora se enuncian de forma más explícita y sistemática.

Juan es el único evangelista que sitúa a Judas fuera del relato de la pasión. Esas dos notas sirven para presentar al personaje y como clave hermenéutica para su comprensión.

Existe un interés especial del narrador de relacionar a Judas con el pan.

El motivo del dinero no está ligado a las autoridades judías, sino al robo a la comunidad, lo cual lo hace similar a los oponentes del buen pastor (Jn 10,7ss). De esta manera, la situación se presenta como una cuestión intracomunitaria.

Judas siempre aparece dentro de las notas del narrador o en versículos comentados por él. Además, esas notas son cristológicas, lo que permite concluir que Judas es contemplado en relación con Jesús y que el interés del narrador es centrar la atención del lector en esa relación para que el lector la comprenda bien.

\section{c) Conclusiones}

Tanto el contenido, la enunciación y la disposición de las noticias sobre Judas en la narración joánica nos permiten extraer algunas conclusiones iniciales.

Juan conoce las tradiciones sinópticas e incluso algunos de los relatos, aunque no dependa literariamente de ellos.

Su particular enunciación, permite deducir que el tema de Judas no es menor para el autor y, por lo tanto, por medio de sus notas quiere 
llamar la atención del lector para que descubra un significado más allá de lo que ocurre en la superficie de los hechos narrados.

Para encontrar ese significado es necesario estudiar las notas dentro del texto, así como la relación que mantienen con los otros enunciados y con otras notas del relato.

\section{LAS NOTAS DEL CUARTO EVANGELIO REFERIDAS A JUDAS}

\section{Las notas de Jn 6,64.71}

Al finalizar el discurso en la sinagoga de Cafarnaúm, el narrador inserta dos comentarios que tienen como objeto a Jesús y como sujeto a Judas.

Jn 6,64 cierra el diálogo entre Jesús y un numeroso grupo de discípulos que consideran sus palabras insoportables (Jn 6,60).

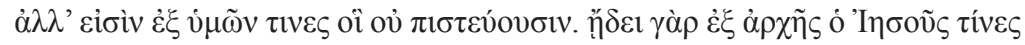

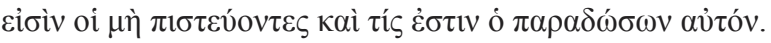

El lector ya sabe que Jesús conoce el interior de las personas y que no se fía de todos sus seguidores (Jn 2,24-25). En esta nota añade el dato de que uno de esos no creyentes lo va a entregar.

Tras el abandono de algunos de los discípulos, Jesús se dirige a los Doce, el diálogo termina con una nueva nota del narrador (Jn 6,71).

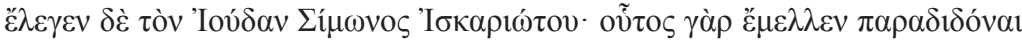

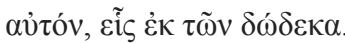

Se identifica a Judas de Simón Iscariote con un diablo, es el que le va a entregar y es uno de los Doce ${ }^{10}$.

Esta información sólo es accesible para los lectores. Es la primera caracterización de Judas que se desarrollará en las siguientes apariciones

${ }^{10}$ Hernández, José Manuel, La caracterización de Jesús en las notas del evangelio de Juan. Un guía de lectura para el relato (=Universidad Pontificia de Salamanca Tesis 254), Universidad Pontificia de Salamanca, Salamanca 2019, 30-31. 
del personaje: aparece como un discípulo que no cree en las palabras de Jesús, pero que lo oculta permaneciendo dentro del grupo de los Doce al que pertenece desde el principio; es un demonio y entregará a Jesús.

\section{a) Estas palabras son escandalosas}

Las dos notas comentan el discurso del pan. La primera lo hace de forma directa y la segunda tras el diálogo con los Doce, pero que de forma implícita también se refiere al discurso anterior, ya que Jesús les pregunta sobre su posición ante sus palabras ¿también vosotros queréis marcharos? (Jn 6,67).

Lo que escandaliza a algunos de los discípulos es el discurso en general: ¿cuál es su contenido? El que busca lo esencial en la vida debe basarse en Dios que se hace presente en su Enviado (Jn 6,25-29). Este es el pan de Dios que da la vida al mundo (Jn 6,30-33). La vida depende ahora del encuentro con Jesús, que posee la vida en plenitud a la que todos los hombres aspiran ( Jn 6,35), porque es el pan que ha bajado del cielo ( $\mathrm{Jn}$ $6,41)^{11}$. La murmuración apunta a este versículo: ¿Cómo va a ser el pan del cielo si es el hijo de José y de María? La voluntad de Dios de dar la vida al mundo se realiza mediante la entrega de Jesús a la muerte para la vida del mundo. Los versículos 51c-58 retoman este motivo para interpretarlo y desarrollarlo a nivel eucarístico. El pan vivo se identifica con la carne y la sangre de Jesús: el pan vivo bajado del cielo es la carne de Jesús para la vida del mundo, vida que se apropia en la eucaristía ${ }^{12}$. Comer el pan eucarístico es la última realización del "comer" mencionado en el v. $31^{13}$.

Así pues, Judas aparece entre los que se escandalizan por la pretensión divina de Jesús (cristología alta) y por la interpretación eucarística del discurso del pan de vida. Es evidente que el Judas "histórico" no responde a esta caracterización crítica con la eucaristía, sino que es pospascual. El narrador al introducir a Judas en este momento tiene la intención de presentarlo de este modo.

${ }^{11}$ Zumstein, Jean, El evangelio según Juan (= Biblioteca de Estudios Bíblicos 152), Sígueme, Salamanca 2016, 288.

${ }^{12}$ ZuMSTEIN, Jean, El evangelio 301.

${ }^{13}$ Schnackenburg, Rudolf, El evangelio según San Juan, Herder, Barcelona 1980, 108. 


\section{b) Es un diablo}

¿Qué es un diablo en el evangelio de Juan? Es el adversario por excelencia $^{14}$. La escena posee un paralelismo con la escena sinóptica de la confesión de Pedro en Cesárea (Mc 8,27-33; Mt 16,13-23; Lc 9,18-22). Pese a las diferencias, que evidencian la independencia literaria, se pueden rastrear elementos comunes (Pedro como portavoz de los Doce, confesión de fe, resistencia por parte de uno de los discípulos) y el traslado de la caracterización de Satanás de Pedro a Judas ${ }^{15}$.

Esto nos invita a no tomar la designación de "diablo" en sentido literal, como un "espíritu" encarnado, sino como un oponente de Jesús, que ocupa, dentro del grupo de discípulos, una posición contraria a sus palabras y a su camino ${ }^{16}$.

Más adelante Jesús designa a los judíos que han creído en él como hijos del diablo. Estos son acusados de no permanecer en él y de querer matarlo (Jn 8,31.37) porque no aceptan su doctrina que viene del Padre $(\text { Jn } 8,43)^{17}$. La oposición de los judíos que habían creído en él se debe a su pretensión divina y al poder de su palabra y le echan en cara, un hipotético origen samaritano y le acusan de tener un demonio (Jn 8,48.51.58b). En estos textos el demonio es caracterizado como mentiroso y homicida, rasgos que se trasladan a sus seguidores, especialmente a Judas: es un discípulo de Jesús que no acepta su palabra, es mentiroso e hipócrita, su deseo de entregar a Jesús coincide con el deseo de matarlo de los judíos creyentes. No es descabellado pensar que el narrador ha caracterizado a Judas con los rasgos de judeocristianos que creían en Jesús y le abandonaron.

\section{c) Uno de los Doce}

El narrador menciona por primera vez al grupo de los Doce. La mención es pertinente, ya que Juan no ha reproducido la lista de los apóstoles en su relato. Estos han cedido su protagonismo en el evangelio joánico a los discípulos, que es la categoría fundamental en el relato. Esta nota se

${ }^{14}$ Wright, William, "Greco-Roman Character Typing and the Presentation of Judas in the Fourth Gospel en The Catholic Biblical Quarterly 71 (2019) 544-559, 553.

${ }^{15}$ Brown, Raymond. E., El evangelio según San Juan I-XII, Cristiandad, Madrid 1999, $582-583$.

${ }^{16}$ Gathercole, Simon, The Gospel of Judas.

${ }^{17}$ Hernández, José Manuel, La caracterización de Jesús 32. 
diferencia y se contraponen las comunidades joánicas con los grupos cristianos que veneraban a Pedro y a los Doce. Sin llegar a rechazar a estos grupos, las comunidades joánicas se consideran más cercanos a Jesús.

El cuarto evangelio destaca la presencia viva de Jesús en los creyentes por medio del Paráclito, y así se convierte en una advertencia frente al peligro inherente en los desarrollos eclesiológicos y sacramentales que habían desarrollado la corriente conocida como la "Gran Iglesia". En estos grupos, los sacramentos pertenecen a la esfera de la vida eclesial, mientras que para los grupos joánicos, los sacramentos son una continuación del poder que Jesús manifestó en su ministerio terreno ${ }^{18}$. Entonces esta nota puede leerse como un reproche a las iglesias apostólicas que concebían de forma distinta el sacramento de la eucaristía.

\section{La nota de Jn 12,6}

Al comienzo del undécimo capítulo el narrador llama la atención del lector sobre la unción de Jesús en Betania, antes de su narración propiamente dicha, lo cual revela el interés por esta escena. En ella Judas juega un papel relevante, algo que no ocurre en los relatos sinópticos ${ }^{19}$.

En Jn 12,1-8 es la única vez que se escucha la voz de Judas en el evangelio. Su discurso parece pragmático, razonable y piadoso, ya que propone que el dinero empleado en el perfume se podía haber utilizado en limosnas para los pobres, una de las obras piadosas judías más valoradas en el judaísmo (Eclo 7,10; Tob 12,8-9) ${ }^{20}$.

El narrador muestra al lector lo que se esconde tras las palabras de Judas

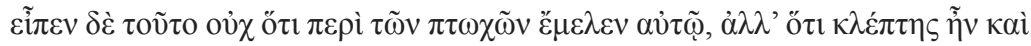

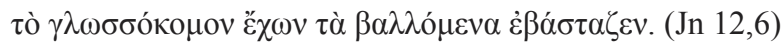

\footnotetext{
${ }^{18}$ Brown, Raymond, La comunidad del discípulo Amado. Estudio de eclesiología joánica (= Biblioteca de Estudios Bíblicos 43), Sígueme, Salamanca, 81-85.

${ }^{19}$ Para conocer la evolución de esta tradición ver MiQuel, Esther, Amigos de esclavos, prostitutas y pecadores: el significado sociocultural del marginado en las éticas de Jesús y los filósofos cínicos, epicúreos y estoicos. Estudio desde la sociología del conocimiento, Verbo Divino, Estella 2009, 308-328; GuIJARro, Santiago-RodríGuEZ, Ana, "La Unción Mesiánica de Jesús" en Salmanticenses 60 (2013) 43-66.

${ }^{20}$ Zumstein, Jean, El evangelio según Juan (1-12) 507.
} 
El motivo del dinero, que aparece en la tradición sinóptica, es recogido aquí y modificado sustancialmente. Judas es el tesorero del grupo de los Doce, lo cual aprovecha para robar el dinero común. El puesto de tesorero muestra su relevancia en el grupo y desvela que Jesús y sus discípulos tenían bienes en común y que repartían limosna. Así se refleja en Jn 13,29.

Judas es presentado como un ladrón $\left(\kappa \lambda^{\prime} \epsilon^{\prime} \tau \eta \zeta\right)$. Esta caracterización lo sitúa en la misma línea que los oponentes al buen pastor que han aparecido en el capítulo 10 (Jn 10,1.8.10) ${ }^{21}$ La caracterización del ladrón en Jn 10,8 va más allá de robar, también mata y destruye.

Que el tema del dinero aparezca de forma independiente al encuentro con las autoridades judías, con las que Judas no se reúne en el relato joánico, y que el perjudicado del robo sea el propio grupo de Jesús invita a pensar que el narrador presenta a Judas y su traición como un problema intracomunitario.

La nota de Jn 12,6 también permite descubrir la semejanza de Judas con el "asalariado" de Jn 10,12-13. Las expresiones del narrador y de Jesús son muy similares

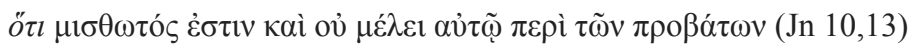

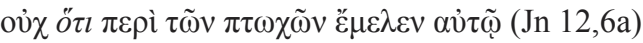

En el discurso del buen Pastor se acentúa el carácter negativo del asalariado (Jn 10,13), mientras el pastor entrega la vida, el asalariado busca su propio beneficio. Judas antepone el amor al dinero al amor a Jesús, como ha mostrado María con el derroche de perfume ${ }^{22}$, y su propio provecho e interés, al contrario que el verdadero pastor. Según Moloney los lectores pueden relacionar al asalariado con los judíos que reiteradamente han rechazado aceptar las afirmaciones que hace Jesús de que él viene de Dios, que junto a Él regresará y que lo da a conocer ${ }^{23}$. Pudiendo estar de acuerdo con esta interpretación, también es cierto que cuando los lectores leen el capítulo 10 no pueden dejar de pensar en cristianos que se dirigen

\footnotetext{
${ }^{21}$ Wright, William, "Greco-Roman Character" 544.

${ }^{22}$ ZuMstein, Jean, El evangelio según Juan (1-12) 508.

${ }^{23}$ Moloney, Francis J., El evangelio de Juan, Verbo Divino, Estella 2005, 319.
} 
a cristianos. De nuevo aparecería un conflicto interno dentro de las comunidades joánicas.

En definitiva, en esta nota Judas aparece caracterizado como un ladrón, amante del dinero, y como un asalariado que traiciona y se aprovecha de las ovejas en beneficio propio.

\section{Judas en la última cena}

El anuncio de la entrega de Jesús por un miembro de los Doce y la identidad del traidor se desvela para los personajes en el transcurso de la última cena tras el lavatorio de los pies, aunque al final solo parece conocerla el discípulo amado. Tres anuncios de la traición de Judas aparecen estratégicamente colocados en el episodio: en el prólogo del narrador (Jn $13,2)$ y las otras dos cerrando cada una de las interpretaciones del lavatorio de los pies (Jn 13,10b-11.18) ${ }^{24}$.

En Jn 13,2 el narrador indica la influencia del diablo en el corazón de Judas (Cf Jn 8,); en Jn 13,11, anota que Jesús conoce al traidor y que este no está limpio; por último, caracteriza su entrega como el cumplimiento de la Escritura (Jn 13,18). Es en la escena que cierra todo el episodio (Jn 13,21-30) donde el traidor es identificado, aunque los discípulos no lo comprendieron, según la información del narrador (Jn 13,28-30). En cambio, el lector descubre el cumplimiento de las notas de Jn 6,64.71 y del cumplimiento del mecanismo a través del cual se va a desarrollar la traición, la cual, a su vez, se presenta como cumplimiento de la voluntad de $\operatorname{Dios}^{25}$.

\section{a) La influencia del diablo en Judas}

El lector conoce que Judas es un traidor y un diablo (Jn 6,64.70-71). Lo que allí se anunció se desarrolla narrativamente en este pasaje. Jn 13,2 anticipa el versículo 27 que da cuenta de la posesión demoníaca de Judas.

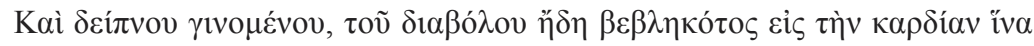

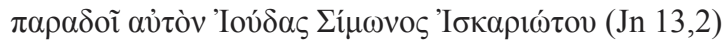

${ }^{24}$ Zumstein, Jean, El evangelio según Juan (13-21) (Biblioteca de Estudios Bíblicos 153), Sígueme, Salamanca 2016, 24.

${ }^{25}$ Hernández, José Manuel, La caracterización de Jesús 36. 
Al comienzo de la cena el diablo ya ha puesto la intención de entregar a Jesús en el corazón de Judas. Lo que traerá consigo el cumplimiento del propósito de los judíos, incluidos los que habían creído en él (Jn $8,37.59$ ). El lector sabe que Jesús ya ha sido condenado por el sanedrín (Jn 11,53) y habían dado orden de denunciarlo (Jn 11,57). Judas será el que cumpla esta orden. Aún no está poseído, pero en la sede de la voluntad y la fuente de las decisiones de Judas ha anidado un propósito. ¿Cuándo y cómo se pasa del propósito a la acción?

El narrador lo hace coincidir con el momento en el que Judas toma el pan que Jesús le da y que tiene como consecuencia la salida de Judas del grupo para introducirse en la noche.

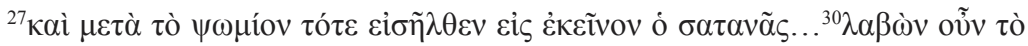

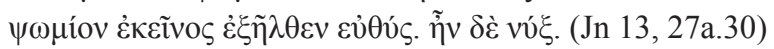

Al tomar posesión de Judas, este se convierte ahora en el demonio que se opone al proyecto de Dios, domina al mundo y busca alejar al hombre de Dios. El mal cósmico que transciende al individuo se sirve de él para llevar a cabo sus planes ${ }^{26}$. Pero pese a ello permanece bajo el control de Jesús que ordena al demonio que cumpla con su tarea sin dilación ${ }^{27}$. Al mismo tiempo que el diablo toma posesión de Judas este abandona el círculo de los discípulos, deja de formar parte de los amigos de Jesús. Se aleja definitivamente de la Luz verdadera para formar parte de las tinieblas $(11,10-11)^{28}$.

Judas ha sucumbido ante el poder del mal y ha abandonado el grupo. Su figura es signo de la falibilidad de la Iglesia. Justo cuando la comunidad aparece como un grupo distinto del mundo, permanece expuesta al mal y al pecado: la comunidad no es impecable y el hecho de que uno de los íntimos ha entregado a Jesús se lo recuerda constantemente ${ }^{29}$.

${ }^{26}$ ZuMStein, Jean, El evangelio según Juan (13-21) 31.

${ }^{27}$ Entre los signos de Jesús recogidos en el cuarto evangelio no se encuentra ningún exorcismo. Sin embargo, en esta escena se descubre la "autoridad" de Jesús sobre el endemoniado.

${ }^{28}$ Zumstein, Jean, El evangelio según Juan (13-21) 51.

${ }^{29}$ ZuMSTEIN, Jean, El evangelio según Juan (13-21) 52. 


\section{b) "No estáis limpios todos"}

Jesús en su diálogo con Pedro desvela que uno del grupo no está limpio. El narrador anota que se refiere a Judas. Más adelante Jesús relaciona la limpieza con la recepción de sus palabras (Jn 15,3-5). La pureza es un término relacional que expresa el estado necesario para el acceso a Dios y a la comunión con él. Estar puro y tener parte con Jesús es una misma $\operatorname{cosa}^{30}$. La separación de Jesús se produce cuando no se acoge su palabra, lo que confirma la primera caracterización de Judas en Jn 6,64 en la que se encuentra entre los que creen que las palabras de Jesús son intolerables $^{31}$. Esto hace que Judas se haya alejado de la intimidad de Jesús y el diablo haya podido influir en su voluntad.

c) “El que comía mi pan levantó contra mí su talón” Jn 13,18

Jesús confirma que conoce al que lo va a entregar y que, además, es el cumplimiento del plan de Dios manifestado en la Escritura ${ }^{32}$.

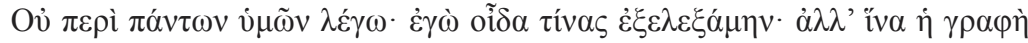
$\pi \lambda \eta \rho \omega \theta \tilde{n}$.

$\dot{o} \tau \rho \omega ́ \gamma \omega \nu$

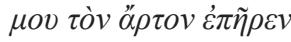

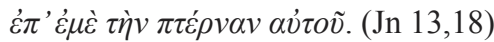

¿De qué Escritura se trata? Prácticamente todos los estudiosos descubren tras la cita el Salmo 40,10 (LXX)

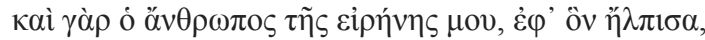

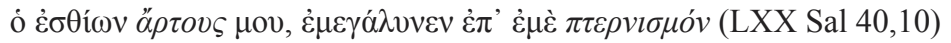

${ }^{30}$ ZuMstein, Jean, El evangelio según Juan (13-21) 35.

${ }^{31}$ WrIGHT, William, "Greco-Roman Character" 556.

${ }^{32}$ DAly-Denton, Marie, David in the Fourth Gospel: the Johannine Reception of the Psalms (=Arbeiten zur Geschichte des antiken Judentums und des Urchristentums 47), Brill; Leiden- Boston, 198-201). La autora contempla que la cita recoge también la experiencia de la comunidad joánica, la cual es denunciada por personas cercanas a ellos o por discípulos apóstatas (3Jn 10;2Jn 7). 
Esta conclusión no es tan sencilla, pues el tenor de la cita no coincide ni con el texto de la Septuaginta ni con el texto hebreo. La cita es fruto de la exégesis joánica, que aúna distintos textos análogos para interpretarlos de forma conjunta ${ }^{33}$.

Más adelante, Jesús desvela la identidad del traidor al discípulo amado por medio de un gesto simbólico que coincide con el contenido de la cita del Sal 40:

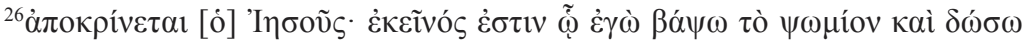

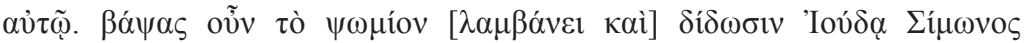

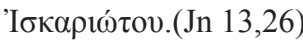

Si bien la temática eucarística no se encuentra en el centro del pasaje, sí aparece claramente en el trasfondo sobre todo en las escenas que se refieren a Judas. Varios indicios muestran el interés por relacionar estos tex-

${ }^{33}$ Menken, Maarten J. J., “The Translation of Psalm 41,10 in John 13,18”, Journal for the Study of the New Testament 40 (1990) 61-79, pp. 68-69. Este fenómeno se da en otras citas de la Escritura a lo largo de todo el evangelio. Bynum ofrece una explicación muy plausible para esta circunstancia, defiende que en los últimos años se ha renovado la confianza en la fiabilidad de las citas escriturísticas del cuarto evangelio. Esto, junto con la mayor comprensión del texto de las Escrituras y de su desarrollo en el s. I, ofrecen la posibilidad de una mayor comprensión de la forma en que Juan cita las Escrituras. El evangelista quiere persuadir a sus lectores u oyentes de la exactitud de su interpretación cristológica, la cual se apoya, en numerosos casos, en la Escritura y en concreto en varias notas del narrador (Jn 2,22), por lo que no utilizaría citas que ofenderían por su inexactitud. El uso de la las Escrituras en el evangelio demuestra la sensibilidad del autor con las prácticas judías contemporáneas y revelaría un elemento vital de su estrategia para caracterizar a Jesús. La interpretación cristológica y la remodelación creativa de las tradiciones disponibles no le obligan a una única práctica exegética. Es evidente que ni en el judaísmo, ni en el cristianismo primitivo existía una preocupación por tener una forma única y precisa de las escrituras: no había un solo texto universalmente aceptado en esa época, lo cual no significaba que no se considerasen sagrados. El autor del evangelio habría tenido la posibilidad de varias tradiciones textuales en un mundo de textos bíblicos caracterizado por la pluriformidad, y su uso estaría en consonancia con esa pluralidad y con las prácticas exegéticas de la época (BYNum, Wm. Randolph., "Quotations of Zechariah in the Fourth Gospel”, en: MyERs, Alicia D. - Schuchard, Bruce G.(eds), Abiding Words: the Use of Scripture in the Gospel of John (=Resources for Biblical Study 81), SBL Press, Atlanta 2015, 57-58). Todo lo que Bynum dice del autor se puede atribuir también al narrador, especialmente al narrador y a sus notas, pues en ellas se citan expresamente las escrituras, o las interpretan o se remiten a ellas para caracterizar a Jesús. 
tos con la eucaristía y con las tradiciones eucarísticas de la comunidad joánica $^{34}$. La cita explícita de la Escritura muestra que el cuarto evangelio pone más énfasis que los sinópticos en relacionar la traición de Judas con la última cena (Mc 14,18; Mt 26,3; Lc 22,21). En segundo lugar, la cita

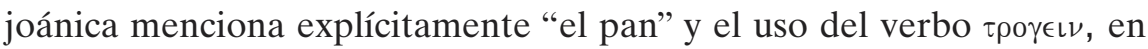
lugar del original de la LXX, lo cual le relaciona con el discurso del pan de vida, ya que este termino solo aparece en el relato en Jn 6,54.56.57.58 en el que por primera vez se anunció la traición de Judas (Jn 6,64.70-71). Justamente en el pasaje con más características eucarísticas del evangelio.

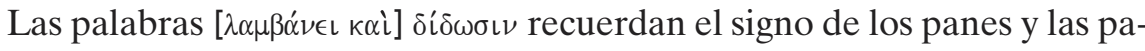
labras sobre el pan en la última cena:

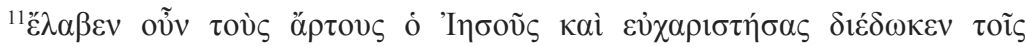

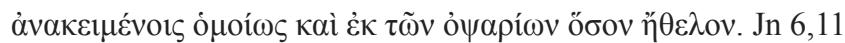

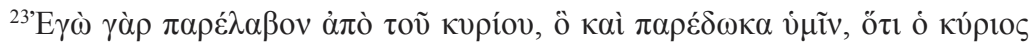

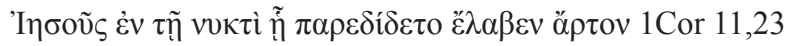

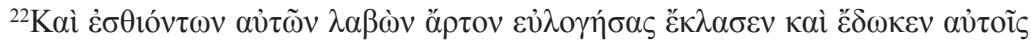

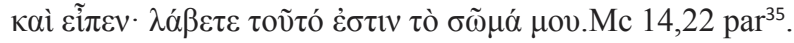

Se puede interpretar que Jesús ofrece a Judas, al discípulo que sabe que va a entregarlo, la prenda de su amor incondicional simbolizada en el bocado $^{36}$. Este gesto escandaliza a Judas y hace posible que Satanás se apodere definitivamente de él y casi simultáneamente abandone la estan-

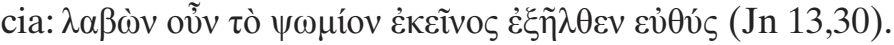

Si no se pierde de vista la intencionada caracterización eucarística de la escena y la información de que Judas consideraba intolerable la enseñanza sobre ella (Jn 6,54-58) se puede deducir que aquí aparece el definitivo rechazo por parte de Judas de la concepción eucarística de las comunidades joánicas. En español hay dos expresiones que nos pueden

${ }^{34}$ Moloney, Francis J., El evangelio de Juan 396-397; Zumstein, Jean, El evangelio según Juan (13-21) 50.

${ }^{35}$ La lectura dudosa de $\lambda \alpha \mu \beta \alpha \dot{\nu} \nu \in\llcorner\kappa \alpha \grave{l}$, omitida en importantes manuscritos y códices, se puede considerar como una lectura original por tratarse de la lectio difficilior, ya que los escribas ven la dificultad de interpretar el bocado dado a Judas eucarísticamente, y porque apoya los otros indicios eucarísticos que aparecen en el episodio. MolONEY, Francis J., El evangelio según Juan 400.

${ }^{36}$ Moloney, Francis J., El evangelio según Juan 388. 
ayudar a comprender lo que aquí se narra. La primera es "hacer comulgar con ruedas de molino" que es hacer creer en algo que difícilmente podría ser posible o que alguien nos quiere hacer creer algo imposible. La última oferta de amor de Jesús se convierte para Judas en algo intolerable y una imposición, lo cual permite a Satanás apoderarse de él. La otra expresión es "me llevan los diablos" que en uno de los significados es enojarse mucho; se podría decir que, a Judas, poseído por Satanás, "le llevan los diablos" y abandona la estancia y la comunidad. Definitivamente Judas ha rechazado a Jesús ${ }^{37}$.

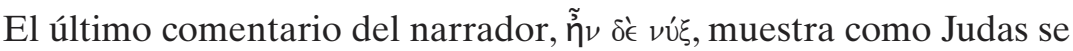
aparta de la luz del mundo $(8,12 ; 9,5)$ y se introduce en la oscuridad de los que rechazan a Jesús y tratan de matarle $(1,5 ; 8,12 ; 9,4 ; 11,10 ; 12,35.46)^{38}$. Pero sobre todo implica que Judas abandona el círculo de los discípulos y deja de formar parte de los amigos de Jesús ${ }^{39}$. Se convierte en un apóstata.

d) Las palabras de Jesús a Judas y el desconocimiento de los discípulos

Judas, incluso poseído por el diablo, no se sustrae a la autoridad de Jesús que le ordena hacer lo que tenga que hacer con rapidez. Jesús no pierde el control de su destino para realizar su misión, incluso se puede decir que él mismo la dirige ${ }^{40}$. Algo que se manifiesta en la escena del prendimiento.

El narrador anota que los discípulos no entendieron el gesto de Jesús ni comprendieron las palabras que dirigió a Judas. Los discípulos las interpretan desde lo que conocen de Judas, es el tesorero del grupo, y que los lectores solo conocen gracias al narrador (Jn 12,1-6). Su falta de inteligencia tiene el aspecto positivo de ser prueba de su inocencia: gracias a ella no son cómplices de la traición que se avecina ${ }^{41}$.

Los estudiosos están divididos a la hora de afirmar o no que el discípulo amado conozca la identidad del traidor. Narrativamente lo más plau-

\footnotetext{
${ }^{37}$ Moloney, Francis J., El evangelio según Juan 396.

${ }^{38}$ Moloney, Francis J., El evangelio según Juan 397.

${ }^{39}$ Zumstein, Jean, El evangelio según Juan (13-21) 51.

${ }^{40}$ Zumstein, Jean, El evangelio según Juan (13-21) 51.

${ }^{41}$ Zumstein, Jean, El evangelio según Juan (13-21) 51.
} 
sible es que este discípulo es capaz de interpretar el gesto de Jesús hacia Judas y por lo tanto de identificarlo como tal. Esta capacidad del discípulo se recuerda en un comentario del narrador en el capítulo 21 del evangelio:

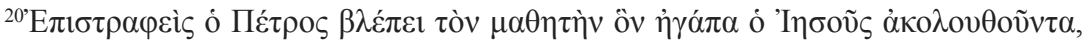

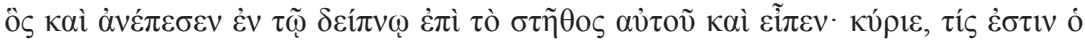
$\pi \alpha \rho \alpha \delta i \delta o u ́ \varsigma \sigma \varepsilon ;$

El discípulo amado es introducido en esta escena por medio de la evocación de todo el episodio de la cena (Jn 13,2.21.25), especialmente por su posición única respecto de Jesús, que recuerda su intimidad y su función de intérprete respecto al Maestro ${ }^{42}$. Pero al recordar su posición también se trae a la memoria el contenido de la revelación. ¿Por qué? El autor quiere establecer una asociación y una distinción entre el discípulo amado y Pedro y este episodio le proporciona un buen telón de fondo ${ }^{43}$. Pero no se debe obviar que a la vez se recuerda que algo que les distingue es que el discípulo amado era capaz de identificar al traidor, mientras que Pedro no adquirió esa capacidad. En un momento de incorporación de las comunidades joánicas a la Gran Iglesia, amenazada por su división interna, el evangelista recuerda esa capacidad de los grupos joánicos de identificar a los apóstatas.

\section{El arresto de Jesús}

La última mención explícita de Judas se encuentra en la escena del prendimiento en Jn 18,1-10. El narrador se refiere a él en dos notas:

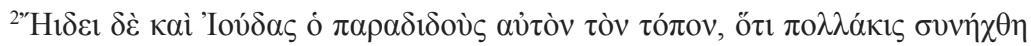

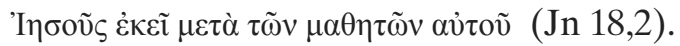

El narrador confirma la pertenencia de Judas al grupo de discípulos ya que conoce el lugar donde Jesús se reunía a menudo con ellos. La no-

${ }^{42}$ Zumstein, Jean, El evangelio según Juan (13-21) 399.

${ }^{43}$ Moloney, Francis J., El evangelio según Juan 565. 
vedad es que ahora forma parte del grupo que arrestará a Jesús como anota el narrador en Jn 18,5c:

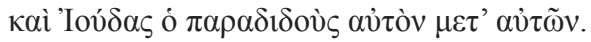

En Jn 18,3 se sugiere que Judas actúa como guía del grupo que se dirige a prender a Jesús. Más allá de esto su papel en el arresto es más bien pasivo $^{44}$. No le identifica con un beso, ni por medio de otra señal, pues Jesús mismo se identifica convirtiendo esta escena en una auto manifestación soberana.

Lo más significativo de la escena es la descripción del grupo que va en busca de Jesús. Además de Judas forman parte de él romanos, guardias judíos mandados por saduceos y fariseos. Son los elementos del mundo y de las tinieblas que se unen contra Jesús, la luz del mundo (Jn 8,12;9,5 ${ }^{45}$. Todos ellos pertenecen a la noche, a la que se ha sumado Judas, por eso necesitan llevar antorchas y tinieblas ${ }^{46}$.

\section{Conclusión}

En el cuarto evangelio Judas aparece como un personaje muy elaborado por el narrador. ¿Cuál es el resultado de esta interpretación? Es presentado como un judeo-cristiano que se escandaliza de la enseñanza eucarística de Jesús. Considera intolerables las palabras de Jesús por eso "no está limpio lo que le convierte en un "diablo". De hecho, es poseído por el demonio al comer el pan en la última cena, que se convierte en el desencadenante de la entrega de Jesús. Esto le hace asemejarse a otros judíos que han creído en Jesús, denominados "hijos del diablo", que no pueden escuchar sus palabras (Jn 8,37.43) ni aceptan las afirmaciones sobre el origen divino de Jesús (Jn 8,57-59). Se completa esta caracterización con los rasgos de mentiroso y ladrón, como los oponentes del Buen Pastor. Que Judas no tenga relaciones con los Sumos Sacerdotes para entregar a

${ }^{44}$ Brown, Raymond E., La muerte del Mesías. Desde Getsemaní hasta el sepulcro, Verbo Divino, Estella 2005, 318.

${ }^{45}$ Moloney, Francis J., El evangelio de Juan 491.

${ }^{46}$ Brown, Raymond E., La muerte del Mesías 320. 
Jesús, que robe a la propia comunidad, que se parezca a los asalariados del rebaño y que sobre su destino solo sepamos que abandona el grupo para salir a la noche y unirse a los que caminan en la oscuridad, permite contemplar esta figura y todas sus circunstancias como un problema intracomunitario.

La caracterización de Judas es claramente pospascual. ¿Por qué le caracteriza de esta forma? La razón más importante parece ser que quería que sus lectores consideraran a Judas como representante de los nuevos apóstatas ${ }^{47}$. Dicho esto, este retrato de Judas se puede considerar como un intento de explicación del por qué entregó a Jesús. La plausibilidad histórica de esta explicación excede los límites del objetivo de este trabajo.

\section{UNA APROXIMACIón Histórica AL "JUdAS DEL CUARTo EVANGELIo"}

¿Es correcta la conclusión que acabamos de extraer? En este apartado rastrearemos si la imagen que el cuarto evangelio transmite de Judas posee alguna base real o es una creación literaria sin arraigo en la historia.

\section{Grupos judeocristianos en el evangelio joánico}

La conocida propuesta de Brown señala la existencia de iglesias judeo-cristianas de fe inadecuada en el tiempo en que se escribió el evangelio, con las que las comunidades joánicas mantienen una actitud hostil a finales del s. I.

El término "judeocristianismo" tiene un significado complicado. En un principio se trata de personas convertidas del judaísmo al cristianismo. Tras la caída de Jerusalén y la expansión de la corriente helenística en el cristianismo se van a ir quedando aislados del resto del movimiento cristiano, convirtiéndose en un conglomerado de grupos distintos ${ }^{48}$.

${ }^{47}$ OropeZa, B.J., "Judas'Death and Final Destiny in the Gospels and Earliest Christian Writings", en Neotestamentica 44 (2010) 342-361.

${ }^{48}$ Rivas, Fernando, "El nacimiento de la gran Iglesia”, en Aguirre, Rafael, (ed), Así empezó el cristianismo, Verbo Divino, Estella, 450-451. Para una acertada y sencilla introducción al judeocristianismo ver GIL, Carlos, "Judeocristianos de Jerusalén” en Reseña Bíblica 44 (2004) 13-21. 
Estos grupos aparecerían en Jn 6,60-66 y en Jn 8,31.44. Son judíos que creyeron en Jesús, pero ahora permanecen como judíos y para el evangelista no son mejores que ellos. Todos ellos se atribuyen la protección de Santiago y de los hermanos del Señor que insisten en la importancia de la descendencia física judía. Poseen una cristología baja y rechazan una concepción de la eucaristía altamente sacramental, como la que presenta el evangelio joánico. No significa que no acepten la eucaristía, sino que no compartían la concepción específica de las comunidades joánicas ${ }^{49}$.

El origen de la Eucaristía no fue un proceso uniforme, no responde a la aparición de un núcleo originario claro y un desarrollo lineal. Existen testimonios en el cristianismo de los orígenes que no responden al esquema "pan-vino". De hecho, algunos grupos celebrarían con agua, como parece indicar (1Cor 10,1-11) y atestigua claramente Cipriano (Carta 63, $1.14)^{50}$. No sería extraño que entre la gran pluralidad de celebraciones eucarísticas las comunidades joánicas fuesen críticas con aquellas que no coincidían con su concepción sacramental. Entre estos grupos destacarán los ebionitas: creyentes en Jesús que vivían como judíos; negaban la alta cristología establecida en Palestina y en la Diáspora. Estamos pensando en un amplio espectro de grupos en la región siro-palestinense. Probablemente estaban más integrados en las sinagogas que en los grupos cristianos en el siglo II ${ }^{51}$.

\section{Los disidentes de las cartas joánicas}

Los errores combatidos en las cartas joánicas no se identifican totalmente con ninguna de las manifestaciones consideradas heréticas posteriormente. Estos errores responden a distintos grupos que defienden una mentira cristológica y practican un indiferentismo moral. Pero todas ellas tienen algo en común: la subestimación de la persona de Jesús y la nega-

${ }^{49}$ Esta posibilidad se ve confirmada por la nota del narrador de Jn 7,5 en la que el narrador declara abiertamente que los hermanos de Jesús no creían en él. Brown, Raymond, La comunidad del discípulo Amado 72-79.

${ }^{50}$ AgUiRre, Rafael, "Rito de pertenencia: comidas eucarísticas" en AgUIRRE, Rafael (ed), Así vivían los primeros cristianos. Evolución de las prácticas y de las creencias en el cristianismo de los orígenes, Verbo Divino, Estella 2017 (157-209), 190-194.

${ }^{51}$ Dunn, James, Ni judio ni griego. Una identidad cuestionada, Verbo Divino, Estella 2018, 623-627. 
ción de la salvación a través de la carne y de la sangre ${ }^{52}$. En este apartado describiremos la caracterización de los cismáticos joánicos para estudiar las semejanzas o diferencias con la caracterización del Iscariote.

\section{a) La cronología de las cartas}

Aceptamos la cronología epistolar que presenta el profesor Guija$\mathrm{rro}^{53}$. Este autor defiende que la composición de las cartas está relacionada con la composición del evangelio, ya que se elaboran en un mismo contexto y en un mismo grupo de comunidades. Según su análisis, la cronología más probable es la inversa a la que se presenta en las ediciones del Nuevo Testamento, es decir: 3Jn, 2Jn y $1 \mathrm{Jn}$.

La tercera carta se habría escrito antes de la escisión comunitaria. En ella se reflejan las diferencias entre dos dirigentes de las comunidades. La segunda carta se redacta en el momento inicial de la ruptura, en ella se afirma claramente que los rivales han salido al mundo, confiesan que Jesús no ha venido en la carne y se han convertido en anticristos y seductores, por lo cual no se les debe recibir en el seno de las comunidades (2Jn 7.10). La primera carta de Juan se escribe cuando el conflicto ya se ha generalizado, más que una carta es un verdadero tratado en el que más profundamente se retrata a los rivales, por lo que la dedicamos un apartado específico

\section{b) Los rivales en la primera carta de Juan}

En este escrito se dibuja de forma más minuciosa a los secesionistas. Son aquellos que caminan en tinieblas (1Jn 1,6;2,9.11); son mentirosos (1Jn 2,4;2,22; 4,20); se les llama anticristos (1Jn 2,18;4,13); son apóstatas, pues salieron de los grupos joánicos (1 Jn 2,19) y no se ocupan de los pobres (1Jn 2,11;3,17-18); el mundo los escucha (1Jn 4,5).

${ }^{52}$ Schnackenburg, Rudolf, Cartas de San Juan, Herder, Barcelona 1980, 58-66. Aunque este autor postula que estos grupos secesionistas tienen una orientación gnóstica y tienen su origen entre los círculos cristianos provenientes del paganismo, no se debe olvidar que grupos judeocristianos también asumieron una inspiración gnóstica como testimonia el escrito apócrifo El evangelio de Judas (Bermejo, Fernando, El evangelio de Judas).

${ }^{53}$ Guijarro, Santiago, Los cuatro evangelios (= Biblioteca de Estudios Bíblicos 124), Sígueme, Salamanca 2010, 460-462. 
Estas características coinciden globalmente con la caracterización de Judas en el evangelio y en las notas del narrador. Judas abandonó el grupo y salió en la noche para caminar en las tinieblas. Es identificado con un demonio, ahora a los apóstatas se les denomina anticristos. En ambos casos no se está hablando de un personaje mítico, sino de opositores a Cristo. Asociado a esta última caracterización, tanto Judas como los opositores aparecen como mentirosos, en el caso de los cismáticos, como seductores. Los opositores no se ocupan de los pobres, como a Judas tampoco le interesan.

Brown no contempla entre las áreas conflictivas la concepción de la Eucaristía, algo que hemos visto que caracterizaba al personaje de Judas de forma relevante. Tal ausencia puede explicarse por el distinto contexto geográfico en el que las cartas se escriben y que los grupos judeocristianos no eran allí tan significativos, lo cual no quiere decir que hubiesen desaparecido o el conflicto se hubiese resuelto en otros territorios.

Esto lo vienen a confirmar los escritos de Ignacio de Antioquía, que afronta la tergiversación de la fe desde la tradición, firmemente encarnacional y sacramental, del catolicismo siríaco ${ }^{54}$. En sus cartas podemos encontrar referencias sobre corrientes a los que él considera heterodoxas que tendrían gran cercanía al judaísmo en algunos temas y por otro a una cristología doceta. No se puede considerar estas tendencias con un solo movimiento. El padre apostólico se enfrenta a judíos cristianos que se abstienen de la Eucaristía porque no confiesan que sea la carne de Jesucristo (Esm 7,1) y que mantienen una vida al "modo judío" (Magn 10,3; Cf. 8,1; Fil 6,1-2) $)^{55}$.

\section{c) Conclusión}

En las cartas de Juan se presenta el desarrollo de un conflicto intracomunitario. Los secesionistas presentan una caracterización similar a la de Judas en el evangelio de Juan. Es cierto que no aparecen los mismos términos, pero el contenido es fundamentalmente el mismo: no permane-

${ }^{54}$ Trevijano, Ramón, Patrología (Sapientia Fidei 5), BAC, Madrid 1994, 35.

${ }^{55}$ Rivas, Fernando, "Ignacio de Antioquía” en Aguirre, Rafael (ed), Así empezó el cristianismo, Verbo Divino, Estella 2011, 377. 
cen en las palabras de Jesús, pertenecen a las tinieblas, se oponen a Cristo, mentirosos e indiferentes ante el destino de los pobres.

Esta caracterización es muy general porque engloba a distintos grupos y tendencias heterodoxas. De todas ellas Judas se ha convertido en el prototipo para el autor (o autores) de las cartas para caracterizar a todo aquel que se ha separado de la comunidad ${ }^{56}$.

\section{Conclusión}

Judas es objeto de una relectura profunda y original en el evangelio de Juan. Su caracterización es realizada, principalmente, por medio de la voz del narrador a través de sus notas, lo cual evidencia el interés del autor por llamar la atención de los lectores sobre el traidor.

La caracterización de Judas ha tomado como base los rasgos de los grupos judeocristianos con una fe deficiente, sobre todo en el significado de la Eucaristía y la divinidad de Jesús. Corrientes con estas características aún perviven en tiempos de Ignacio de Antioquía.

El "Judas del evangelio de Juan" se ha convertido en el apóstata por excelencia y sus rasgos más relevantes son adjudicados a los oponentes de la comunidad joánica.

Estos resultados no resuelven la clásica pregunta de "¿por qué Judas entregó a Jesús?”, ni si Judas perteneciese a esos grupos o que fuese una figura relevante dentro de ellos (algo así sería del todo punto inverosímil). Pero no es descabellado pensar que Judas fue "uno de los Doce" cercano a aquellas posiciones y que escandalizado y decepcionado abandonó el grupo y entregó a su Maestro. Algo que se puede tener en cuenta en el espinoso estudio sobre la figura histórica de Judas Iscariote.

${ }^{56}$ No es difícil imaginar que los rivales de los grupos joánicos opinarían cosas parecidas de ellos. De hecho, el Evangelio de Judas es un testimonio, en cierto modo, de que la figura de Judas es utilizada para criticar a los oponentes. Es muy sugerente la idea de que el Evangelio de Judas sea un escrito que polemiza con la Gran Iglesia. De manera ingeniosa presentaría un evangelio en el que Judas ocupa el lugar de Pedro. De esta forma mostraría que la "ideología sacrificial ortodoxa" bien podría tener como garante e iniciador a Judas Iscariote y, por tanto, es un culto que no se corresponde con la revelación de Jesús. 